\title{
Choroid plexus papilloma in an adult ewe - a case report
}

\author{
Jose María González ${ }^{1}$, Delia Lacasta ${ }^{2}$, Santiago Sanz ${ }^{2}$, María Climent $^{3}$, Alicia Uixera ${ }^{2}$, \\ Luís Miguel Ferrer ${ }^{2}$, Marta Borobia ${ }^{2}$, Araceli Loste ${ }^{2}$, Juan José Ramos ${ }^{2}$ \\ ${ }^{1}$ Gabinete Técnico Veterinario S.L., Zaragoza, Spain \\ ${ }^{2}$ University of Zaragoza, Veterinary Faculty, Animal Pathology Department, \\ Zaragoza, Spain \\ ${ }^{3}$ University of Zaragoza, Veterinary Faculty, Anatomy, Embryology and Genetics Department, Zaragoza, Spain
}

Received October 3, 2012

Accepted November 29, 2012

\begin{abstract}
Primary neoplasms of the central nervous system have been rarely reported in sheep. A threeyear-old Rasa Aragonesa ewe was admitted to the small ruminant external consultancy at the Veterinary Faculty of University of Zaragoza, Spain. Clinical, haematological and neurological examinations were performed. Neurological examination showed signs of ataxia, hyperextension of the right front limb and abnormal postural reactions. The animal was unable to stand and walk, even with help. Patellar and flexor reflexes were normal and superficial sensation was present but decreased. Humanitarian sacrifice was carried out one month later. Gross and histopathological findings revealed a choroid plexus papilloma located in the fourth ventricle of the brain. To the authors' knowledge this is the first description of this neoplastic disorder in sheep.
\end{abstract}

Sheep, central nervous system, pathology, choroid plexus papilloma, primary neoplasm

Primary neoplasms of the central nervous system (CNS) have been rarely reported in sheep (Olson et al. 1981; González et al. 1994; Oda et al. 1997; Roels et al. 2001; Zanolari et al. 2004; Ortin et al. 2006; Derakhshanfar and Mozaffari 2010). Choroid plexus papilloma in sheep and goat has not been described in the literature. Furthermore, only three cases of this tumour have been reported in cattle (Luginbuhl et al. 1968; Yamada et al. 1998; Hoenerhoff et al. 2006).

The present report describes the clinical presentation and histopathological findings of an ovine choroid plexus papilloma.

\section{Clinical presentation}

A three-year-old Rasa Aragonesa ewe was admitted to the small ruminant external consultancy at Veterinary Faculty of University of Zaragoza, Spain. The affected ewe showed neurological signs. The animal had a 2-week history of progressive ataxia, followed by recumbency, holding the head to the right side (Plate I, Fig. 1).

The ewe was kept at the facilities for one month and clinical, haematological and neurological examinations were performed. At examination, the ewe showed normal heart and respiratory rates $(105$ beats $/ \mathrm{min}$ and $58 \mathrm{bpm})$ and rectal temperature was $39{ }^{\circ} \mathrm{C}$. Haematological indicators retrieved were within the normal range. Neurological examination confirmed signs of ataxia. Hyperextension of the right front limb and abnormal postural reactions were observed. The animal was unable to stand and walk, even with help. Patellar and flexor reflexes were normal and superficial sensation was present but decreased.

\section{Post mortem findings}

Due to the poor body condition and bad prognosis, the animal was euthanized. A humanitarian sacrifice was carried out with $200 \mathrm{mg}$ pentobarbital sodium (product Dolethal ${ }^{\circledR}, 0.7 \mathrm{ml} / \mathrm{kg}$, Vetoquinol UK Ltd.), and necropsy was performed.

Address for correspondence:

Dra. Delia Lacasta

Animal Pathology Department.

Veterinary Faculty, University of Zaragoza

C/Miguel Servet 177, 50013 Zaragoza, Spain

Phone: +34976 761578

E-mail: dlacasta@unizar.es

http://actavet.vfu.cz/ 
Gross findings revealed a $1 \mathrm{~cm}$ spherical firm mass, originating from the choroid plexus of the fourth ventricle, into which it extended. The mass showed a well-defined papillary growth and the lateral ventricles were slightly dilated probably due to the obstruction of the CSF flow within the ventricular system (Plate I, Fig. 2). Some degree of atrophy was detected in the nearest structures.

Histological evaluation of the tissue stained with haematoxylin-eosin showed the choroid plexus with an exophytic arborizing mass composed of moderate amount of fibrovascular stroma covered with a cuboidal epithelial layer. Mitosis was not present (Plate II, Fig. 3).

\section{Discussion}

Even though neurological disorders of small ruminants have been well defined in standard textbooks (Matin and Aitken 2000; Ferrer et al. 2002), there are not many studies reporting the real prevalence of these diseases. Oevermann et al. (2008) reported the prevalence of brain lesions in the Swiss fallen stock population of small ruminants. Over 3,075 brains were analyzed and lesions were found in an unexpectedly high number of animals $(8.1 \%)$. The results show that inflammatory disorders were the most frequent cause of CNS lesions (74.7\%), followed by toxic/metabolic disorders $(21.9 \%)$, with neoplastic disorders only found in $1.5 \%$ of the analyzed brains. Neoplasms observed included lymphomas, pituitary adenomas and meningeal lipomas; no choroid plexus papilloma was described.

Differential diagnosis for progressive CNS disease in sheep includes infectious diseases such as listeriosis, Aujeszky's disease, Visna Maedi, bacterial meningitis and tetanus; parasitic disease as cenurosis or sarcocystiosis, carential deficiency diseases such as cerebro-cortical necrosis, and degenerative diseases such as as scrapie (Martin and Aitken 2000; Ferrer et al. 2002). There are many different neoplastic diseases; however, they are rare causes of primary CNS disease in adult sheep. Some neoplastic disorders have been reported in sheep (Olson et al. 1981; González et al. 1994; Oda et al. 1997; Roels et al. 2001; Zanolari et al. 2004; Ortin et al. 2006; Derakhshanfar and Mozaffari, 2010) but not a choroid plexus papilloma.

In cattle, three reports describe this neoplastic lesion (Luginbuhl et al. 1968; Yamada et al. 1998; Hoenerhoff et al. 2006). In a series of 1,093 bovine necropsy specimens, Yamada et al. (1998) identified only four primary intracranial nervous system tumours, one of which was diagnosed as a choroid plexus papilloma. In 2006 Hoenerhoff et al. described gross, microscopical, immunohistochemical and ultrastructural findings of a choroid plexus papilloma in a Scottish Highland cow. Furthermore, some descriptions have been reported in other species, for example in dogs (Ribas et al. 1989) where sixteen choroid plexus papilloma tumours were analyzed microscopically.

Neurological signs can be very similar among different disorders, either neoplastic or non-neoplastic ones; for that reason, we would like to emphasize the importance of neuropathology in the diagnosis of ovine neurological diseases. In conclusion, choroid plexus papilloma has to be taken into account as neurological disorder in sheep.

\section{References}

Derakhshanfar A, Mozaffari AA 2010: First report of oligodendroglioma in a sheep. J S Afr Vet Assoc 81: 114-115 Ferrer LM, García del Jalón JA, De las Heras M 2002: Atlas of ovine pathology. Ed. Servet. Spain.

Gonzalez L, Balaguer L, Romano J, Idigoras I, Cuervo L 1994: Prolactinoma in a sheep. J Comp Pathol 111: 321-326

Hoenerhoff MJ, Janovitz E, Ramos-Vara J, Kiupel M 2006: Choroid plexus papilloma in a Scottish Highland cow. J Comp Path 135: 146-149

Lugginbuhl H, Fankhauser R, McGrath JT 1968: Spontaneous neoplasms of the nervous system in animals. Prog Neuro Surg 2: 85-164 
Martin WB, Aitken ID 2000: Diseases of sheep. Blackwell scientific publications. U.K.

Oda S, Wada Y, Kondo H, Ishikawa Y, Kadota K 1997: Pituitary adenoma with prolactin and growth hormone production in a sheep. J Comp Pathol 117: 171-175

Olson DP Ohlson D.L, Davis S.L, Laurence KA 1981: Acidophil adenoma in the pituitary gland of a sheep. Vet Pathol 18: 132-135

Ortín A, Ferrer LM, Loste A, García de Jalón JA, Gómez P, Ramos JJ 2006: Coexistence of pituitary adenocarcinoma and intraocular melanoma in a sheep. Vet Rec 159: 718-719

Oevermann A, Botteron C, Seuberlich T, Nicolier A, Friess M, Doherr MG, Heim D, Hilbe M, Zimmer K, Zurbriggen A, Vandevelde M 2008: Neuropathological survey of fallen stock: active surveillance reveals high prevalence of encephalitic listeriosis in small ruminants. Vet Microbiol 130: 320-329

Ribas JL, Mena H, Braund KG, Sesterhenn IA, Toivio-Kinnucan M 1989: A histologic and immunocytochemical study of choroid plexus tumors of the dog. Vet Pathol 26: 55-64

Roels S, Vanopdenbosch E 2001: B cell lymphoma in the brain of a sheep. Vet Rec 149: 392-393

Yamada M, Nakgawa M, Yamamoto M, Furuoka H, Matsui T, Taniyama H 1998: Histopathological and immunohistochemical studies of intracranial nervous-system tumours in four cattle. J Com Path 119: 75-82

Zanolari P, Botteron C, Jaggy A, Meylan M 2004: Chromophobe adenocarcinoma of the pituitary gland in a ram. J Vet Intern Med 18: 748-752 
Plate I

González J. M. et al.: Choroid plexus ... pp. 9-11

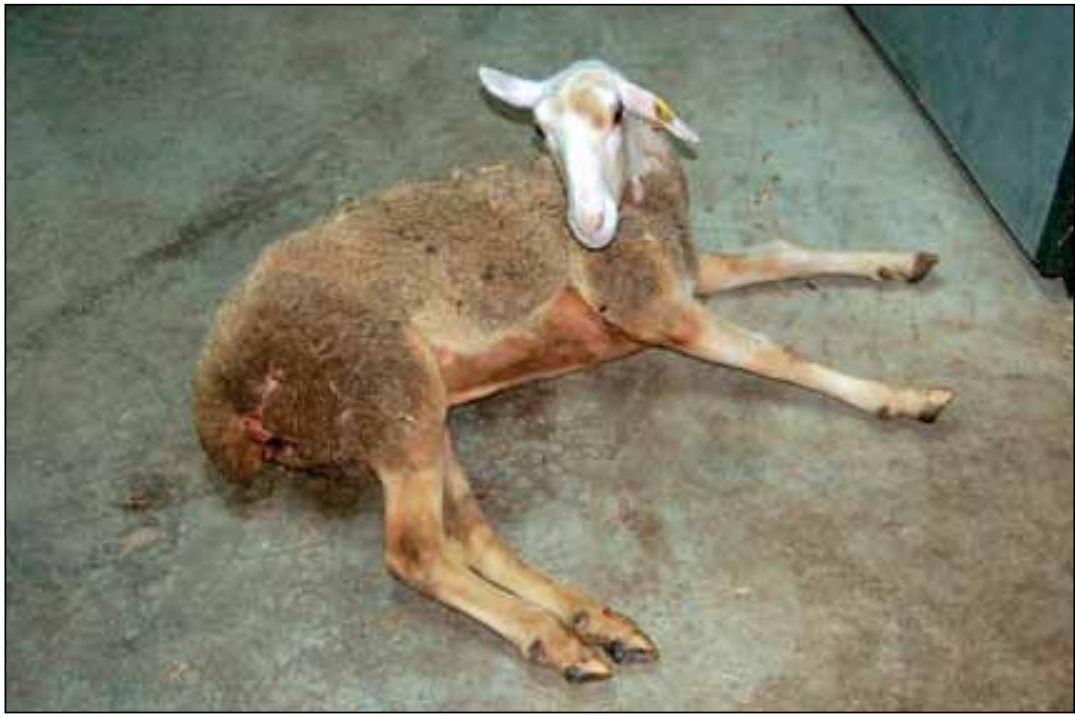

Fig. 1. Ewe showing ataxia, hyperextension of the right front limb and holding the head to the right side.



Fig. 2. Clinical features and gross pathology in cross section of the brain of ataxic sheep showing a $1 \mathrm{~cm}$ spherical firm mass, originated from the choroid plexus of the fourth ventricle. 
Plate II



Fig 3. Choroid plexus papilloma in the ataxic ewe. Haematoxilin-eosin staining, $\times 40$. Bar: $50 \mu \mathrm{m}$. 